REFERENCES

Aeby, C. T. (1880). Der Bronchialbum der Säugethiere und des Menschen. Leipzig.

Ewart, A. (1889). The Bronchi and Pulmonary Vessels. Churchill, London.

Hardie-Neil, J., and Gilmour, W. (1946). N.Z. med. J., 45, 20

Huntington, G. S. (1898). Ann. N.Y. Acad. Sci., 11, 127.

Moolten, Sylvan E. (1935). Arch. Path., $20,77$.

Willis, T. (1676). Pharmaceutice Rationalis de Respirationis Organis et Usu. London.

Illustrations from the References may be seen in the reprint from the New Zealand Medical Journal, 1946, 45, 20, a copy of which is in the B.M.A. Library.

\section{"TRIDIONE*" IN THE TREATMENT OF EPILEPSY}

BY

\section{W. M. WHITTY, M.R.C.P.}

(From the Department of Neurology, Radcliffe Infirmary, Oxford)

The oxazolidine diones, of which tridione is one, are structurally related both to the hydantoins and to the barbiturates. Another member of the series; dipropyloxazolidine dione, had been used some years ago (Luton et al., 1941) as a hypnotic and anaesthetic, and when tridione was synthesized by Spielmann in 1944 it was originally

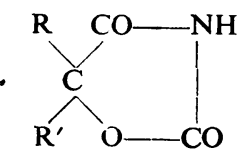

Oxazolidine diores
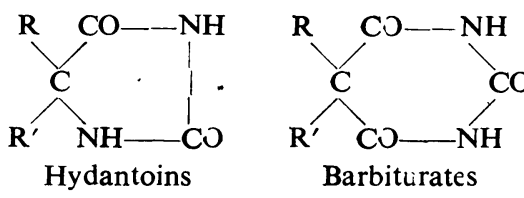

tried as a sedative and analgesic. However, in experimentally induced convutlsions in animals it was found to be more effective as an anticonvulsant than either barbiturates or hydantoins (Everett and Richards, 1944). This observation, combined with the drug's low toxicity, recommended it for the treatment of epilepsy in man, and it has now been in clinical use for some three years.

The first report of its results was given by Lennox (1945), who noted that it was often dramatically effective in the petit-mal epilepsies, but that its expected anticonvulsant action as shown by the control of grand-mal seizures was not pronounced: on the contrary, it appeared occasionally to aggravate these. This view has been largely confirmed by subsequent workers (Richards and Perlstein, 1946; Perlstein and Andelman, 1946 ; Butter, 1948). Its value in psychomotor attacks also seems slight, though De Jong (1946) has claimed on rather slender evidence that, combined with other drugs, it is also effective in controlling these seizures. After two and a half years' experience of its use in 245 patients Davis and Lennox (1947) write of its " unique and almost specific effect in the control of the petit-mal epilepsies." This is a high claim for the treatment of a condition notoriously difficult to control, and may prove over-optimistic. Nevertheless all experience seems to agree that in many cases of petit mal tridione produces a striking amelioration.

Although the drug's toxicity in animal experiments was low, minor toxic effects in man are common. They were discussed in detail by Lennox (1947). He found com-

*"Tridione", is Abbott Laboratories' trade name for 3,5,5trimethyloxazolidine-2,4-dione. It has become established in the literature as the clinical name for this chemical substance and is therefore used here. plaints of a mild photophobia or "glare" effect-so that objects appeared as with a halo when viewed in bright light - the most common. This occurred in about onethird of all patients. Acneiform, morbiliform, and urticarial rashes were also noted, though they were usually transient. Indigestion and nausea might occur. Other occasional symptoms were drowsiness, ataxia, and irritability. Similar effects were reported in this country by Butter (1948). None of these symptoms was a serious hindrance to the continued use of the drug. However, there have also been reports of more severe toxic effects. These are of two main sorts - a reduction of blood-forming activity leading either to agranulocytosis or to aplastic anaemia, and an inflammatory skin reaction which may proceed to exfoliative dermatitis.

Fatal anaemia, or granulocýtopenia, has been recorded in four cases from the United States (Harrison et al., 1946 ; Mackay and Gottstein, 1946 ; Lennox, 1947), but at least one of these was taking "mesantoin" as well as tridione, so that the latter may not have been the responsible agent. In this country also two cases have been reported (Braithwaite, 1948 ; Forster et al., 1949). Similar blood dyscrasias which responded to treatment have been reported in four other cases (Greaves, 1946 ; Briggs and Emery, 1949) ; while Kerrin (1948) detailed a case in which an urticarial rash led on to a fatal exfoliative dermatitis, and Butter (1948) mentioned a similar case which recovered. Barnett et al. (1948) and Briggs and Emery (1949) also record two cases with a nephrotic syndrome, one of which was fatal. These reported figures-eight fatalities and a further six severe reactions-must be considered in the light of Nattrass's (1949) quoted estimate of 10,000 cases that have had tridione treatment. In this context the toxicity of the drug cannot be viewed as very high, and Briggs and Emery must have been particularly unlucky in their experience of four severe reactions in a total of ten patients treated.

Apart from the above effects, Lennox also found that in half the cases of grand mal these fits were made worse.

The drug has not been extensively used in this country, owing partly to difficulties of supply and partly to its reputation for toxicity, which seems to have been exaggerated. Only three series, of 23,10 , and 9 cases respectively (Butter, 1948 ; Briggs and Emery, 1949 ; Nattrass, 1949), have so far been recorded. In this paper the results of the treatment of 50 patients are given.

\section{Present Investigation}

Case Material--Patients were selected in the main because other forms of treatment had failed to control or reduce their attacks. Nineteen were males and 31 females, and their ages ranged from 4 to 62 years. Treatment was continued for periods varying from 2 to 18 months. Some form of the "petit-mal triad"* was present in 46 cases: 22 had only petit-mal epilepsies; the other 24 had grandmal attacks as well. Six of these had proved local brain lesions as the 'probable basis of their attacks. Of the remaining four patients, three had grand mal only, and one a unilateral tremor-rigidity syndrome due to birth injury.

Dosage.-Dosage varied from 0.3 to $1.8 \mathrm{~g}$. of tridione a day, which represented one to six capsules of $0.3 \mathrm{~g}$. each. With adults the initial dose was usually one capsule three

*This nomenclature was introduced by Lennox and Gibbs, and includes "classical" petit mal, myoclonic jerks, and akinetic or inhibitory epilepsy. The grouping seems justified on both clinical and electroencephalographic grounds, and is now accepted, with qualifications, both in this country and in America. 
times a day, which would be scaled up or down in the light of their response. With children under 10, two capsules were used initially, and for those under 5 , one. Once a marked beneficial effect was obtained the dose was usually reduced by stages to the minimum needed to maintain improvement. This was generally two or three capsules a day. Few patients who did not respond to three or four capsules a day would do so with larger doses, though in one case in which the smaller dose had produced no noticeable effect at all doubling the dose-from three to six capsules a day produced a dramatic improvement in 48 hours. In some cases improvement was maintained even when the drug was stopped. For this reason the effect of omitting it was tried in all cases which still maintained improvement with only one or two capsules a day.

\section{Results}

Results were judged by comparing the average number of fits per week before and after treatment. Evidence of this was always obtained from an outside observer as well as the patient. It will be seen from Table I that five of the 22 pure petit-mal cases had their attacks completely

\begin{tabular}{|c|c|c|c|c|}
\hline Case & Age & $\begin{array}{l}\text { Type of } \\
\text { Attacks }\end{array}$ & $\begin{array}{l}\text { Length of } \\
\text { Treatment } \\
\text { (Months) }\end{array}$ & Effect on Attacks \\
\hline $\begin{array}{r}1 \\
2 \\
3 \\
4 \\
5 \\
6 \\
7 \\
8 \\
9 \\
10 \\
11 \\
12 \\
13 \\
14 \\
15 \\
16 \\
17 \\
18 \\
19 \\
20 \\
21 \\
22\end{array}$ & $\begin{array}{r}16 \\
8 \\
17 \\
9 \\
18 \\
10 \\
9 \\
24 \\
11 \\
13 \\
15 \\
9 \\
13 \\
12 \\
9 \\
13 \\
8 \\
16 \\
11 \\
4 \\
18 \\
33\end{array}$ & $\begin{array}{l}\text { Pm., In. } \\
\text { Pm. } \\
\text { Pm. } \\
\text { Pm. } \\
\text { Pm. } \\
\text { Pm. } \\
\text { Pm., In. } \\
\text { Pm. } \\
\text { Pm. } \\
\text { Pm. } \\
\text { Pm. } \\
\text { Pm., Myo. } \\
\text { Pm. } \\
\text { Pm. } \\
\text { Pm. } \\
\text { Pm., Myo. } \\
\text { Pm. } \\
\text { Pm. } \\
\text { Pm., In. } \\
\text { Pm. } \\
\text { Pm. } \\
\text { Pm. }\end{array}$ & $\begin{array}{r}6 \\
4 \\
15 \\
10 \\
8 \\
18 \\
15 \\
4 \\
4 \\
15 \\
15 \\
6 \\
16 \\
4 \\
4 \\
12 \\
6 \\
6 \\
3 \\
2 \\
3 \\
10\end{array}$ & 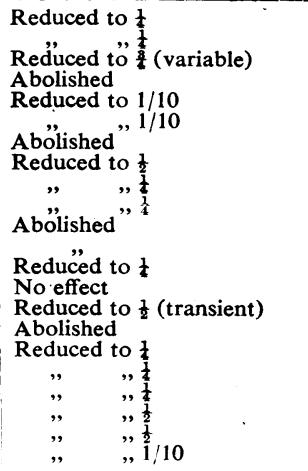 \\
\hline
\end{tabular}

Pm. = Petit mal. In. = inhibitory epilepsy. Myo. $=$ myoclonic jerks

abolished for the period of observation. In a further 11 cases attacks were reduced in frequency to a quarter or less. Another five showed slighter degrees of improvement, which in one case lasted only six weeks. In only one case was there no effect.

The assessment of the cases with mixed grand mal and petit mal is more difficult (see Table II). However, in 15 of them the petit-mal element was abolished or greatly reduced, and in a further five cases it was somewhat reduced. In four it was unaffected. The effect on the grand mal was hard to judge, as these attacks were usually much less frequent than the petit mal. A noticeable reduction of frequency occurred in five cases ; in nine it appeared unchanged; and in ten it increased in frequency, or the fits became more severe, status epilepticus occurring in one case. Reviewing the whole 46 cases from the point of view of petit-mal attacks, 31 showed abolition of attacks or great improvement, 10 showed some improvement, and 5 showed no change; none were worse.

Of the six cases with focal brain lesions the petit mal was unaffected in three. In one, with a frontal glioma, attacks were reduced in frequency from three or four a day to two or three a month. In another, with a right temporal angioma, the petit mal was abolished for five weeks; then a severe status epilepticus occurred and tridione was abandoned. In a third case, with a calcified lesion in the left temporal region, inhibitory or petit-mal attacks were greatly reduced. The drug was stopped in nine cases: in three because improvement was maintained

TABLE II.-Cases with Grand Mal and Petit-mai

\begin{tabular}{|c|c|c|c|c|}
\hline Case & Age & $\begin{array}{l}\text { Type of } \\
\text { Attack }\end{array}$ & $\begin{array}{l}\text { Length of } \\
\text { Treatment } \\
\text { (Months) }\end{array}$ & Effect on Attacks \\
\hline $\begin{array}{l}23 \\
24 \\
25\end{array}$ & $\begin{array}{c}28 \\
42 \\
4 \frac{1}{2}\end{array}$ & $\begin{array}{l}\text { Gm., Pm. } \\
\text { Gm., In. } \\
\text { Gm., Pm. }\end{array}$ & $\begin{array}{l}3 \\
8 \\
4\end{array}$ & $\begin{array}{l}\text { Pm. no effect. Gm. increased } \\
\text { In. abolished. Gm. increased } \\
\text { Both abolished for } 2 / 12 \text {, then } \mathrm{Gm} \text {. } \\
\text { increased }\end{array}$ \\
\hline $\begin{array}{l}26 \\
27 \\
28 \\
29 \\
30 \\
31 \\
32 \\
33 \\
34 \\
35 \\
36 \\
37 \\
38 \\
39 \\
40 \\
41 \\
42 \\
43 \\
44 \\
45 \\
46\end{array}$ & $\begin{array}{l}34 \\
10 \\
29 \\
16 \\
12 \\
18 \\
20 \\
29 \\
22 \\
19 \\
23 \\
23 \\
14 \\
15 \\
12 \\
24 \\
31 \\
18 \\
26 \\
33 \\
31\end{array}$ & $\begin{array}{l}\text { Gm., Myo. } \\
\text { Gm., Pm. } \\
\text { Gm., Pm. } \\
\text { Gm., Pm. } \\
\text { Gm., Pm. } \\
\text { Gm., Pm. } \\
\text { Gm., Pm. } \\
\text { Gm., Pm. } \\
\text { Gm., Pm. } \\
\text { Gm., Pm. } \\
\text { Gm., Pm. } \\
\text { Gm., Pm. } \\
\text { Gm., Pm. } \\
\text { Gm., Pm. } \\
\text { Gm., Pm. } \\
\text { Gm., In. } \\
\text { Gm., In. } \\
\text { Gm., Pm. } \\
\text { Gm., In. } \\
\text { Gm., Pm. } \\
\text { Gm., Pm. }\end{array}$ & $\begin{array}{r}5 \\
>2 \\
4 \\
12 \\
7 \\
16 \\
12 \\
14 \\
4 \\
15 \\
14 \\
10 \\
8 \\
4 \\
6 \\
3 \\
5 \\
4 \\
3 \\
2 \\
5\end{array}$ & 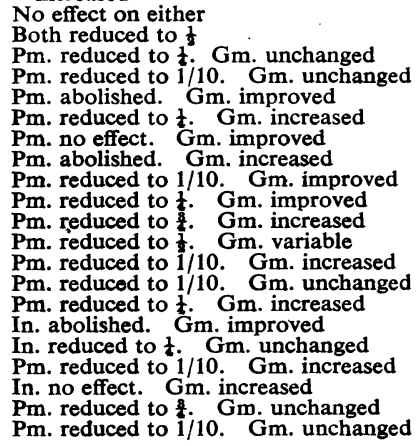 \\
\hline
\end{tabular}

Gm. = Grand mal. In. $=$ inhibitory epilepsy. Pm. = petit mal. Myo. = myoclonic jerks

without it; in two because the effect on petit mal was transient or negligible; in three because grand mal was increased; and in one because of marked irritability and conduct disorder.

Of the three cases of grand mal only, one, a posttraumatic epilepsy from closed head injury, was completely free from fits for a period of over a year. She had been given tridione as both hydantoins and phenobarbitone had failed to reduce the number of her attacks. The other two had been wrongly diagnosed as akinetic attacks before the account of a trained observer made it clear that they were in fact mild grand mal. In neither case was the frequency of the fits affected. The patient with tremor-rigidity syndrome was given tridione for its supposed antispastic effect, but no objective change in his condition was noted after three months' treatment.

In general the results of this regime were shown within a week or ten days of its start. Often within 48 hours a reduction of attacks was remarked on. After three weeks' treatment with an effective dose, further changes in the petit-mal epilepsy were not usually seen, though an increase in grand mal, if it occurred, commonly did so after this time.

If seizures were abolished or much reduced for over three weeks it was usual to start lessening the dose of tridione. In most cases it was possible to do so without any relapse, though occasionally reduction by even one capsule a day caused increase of fits. In three cases the drug was stopped entirely after three to six months of treatment, and all three remained free from attacks for periods of two to four months. On the other hand, in some cases in which the drug was omitted inadvertently attacks recurred or became more frequent within three to four days. Moreover, in two cases omission of the drug because clinical response seemed slight produced an unexpected increase in petit-mal attacks, which were again reduced when it was restarted.

Two cases, one with grand mal only and one with myoclonic jerks and grand mal, showed an interesting 
change in their attacks within ten days of starting tridione. Both noted a lengthening of the period of aura, in each case an epigastric one, so that they were able to sit or lie down before their grand-mal attacks developed, whereas previously they had had only the most momentary warning. They appreciated this change considerably, though in neither case was there any reduction in the frequency of attacks.

\section{Illustrative Cases}

The regime of treatment and the problems involved are illustrated in the following brief case histories.

Case 16: Petit Mal and Myoclonic Attacks Abolished by Tridione.-A boy aged 13 had had typical petit-mal attacks and occasional myoclonic jerks of the right arm and shoulder since the age of $4 \frac{1}{2}$. There was no personal history of grand mal or any family history of epilepsy. Attacks averaged 10 a day, but on bad days he might have 20 or 30 . They were unaffected by $4 \frac{1}{2}$ gr. $(0.29$ g.) of phenobarbitone a day, which was making him sleepy. He was given $0.3 \mathrm{~g}$. of tridione t.d.s and $1 \mathrm{gr}$. $(65 \mathrm{mg}$.) of phenobarbitone b.d. After three days the attacks were much less frequent, and after a week they were abolished. They have been absent now for over a year, except when he omitted the tridione for periods of five and eight days. On each occasion the attacks recurred in 48 hours. He is now stabilized on $0.3 \mathrm{~g}$. of tridione b.d.

Case 5: Petit Mal Controlled by Tridione. Grand Mal Occurred for First Time: Controlled by Hydantoin.-A youth aged 18 had had petit-mal attacks since the age of 7 . There was no personal history of grand mal. One sister had petit mal. Attacks averaged one or two a day and were controlled for some years with $1 \mathrm{gr}$. of phenobarbitone b.d. At the age of 16 attacks recurred, and 1 gr. of phenobarbitone t.d.s. had no effect. He was given $0.3 \mathrm{~g}$. of tridione t.d.s with $1 \mathrm{gr}$. of phenobarbitone b.d. The attacks ceased after 48 hours. The phenobarbitone was gradually reduced during six weeks. Occasional petit-mal attacks recurred three months later, averaging one in four or five weeks. Five months later he had his first grand-mal attack. He had three further attacks in the next 10 days. Then $1 \frac{1}{2}$ gr. $(0.1$ g.) of hydantoin b.d. was added to his tridione. No further grand-mal attack occurred for the next four months. Two petit-mal attacks occurred during this time. $\mathrm{He}$ is now regularly taking $0.3 \mathrm{~g}$. of tridione t.d.s. and $1 \frac{1}{2}$ gr. of hydantoin b.d.

Case 14: Petit Mal Unaffected by Tridione; Grand Mal Developed.-A girl aged 12 had had petit-mal attacks since the age of 10. There was no history of grand-mal attacks, and the family history was negative. The frequency of attacks was 12 daily, and they were reduced in number for a few months by 2 gr. $(0.13 \mathrm{~g}$.) of phenobarbitone a day. This effect soon wore off. She was given $0.3 \mathrm{~g}$. of tridione t.d.s. together with the phenobarbitone, but this was without effect. In one month dosage was increased to $0.3 \mathrm{~g}$. of tridione five times a day. There was no effect in a further month. At this time the first grand-mal attack was reported, and $0.3 \mathrm{~g}$. of tridione t.d.s. with $1 \frac{1}{2}$ gr. of phenytoin sodium ("epanutin") was given for two months. There were no further grand-mal attacks, but the petit mal was unabated. Electroencephalography in this case showed runs of typical wave-and-spike activity.

\section{Electroencephalographic Changes}

A detailed description of these will be given elsewhere. Here it is worth noting that clinical improvement did not always go hand in hand with decreased abnormality in E.E.G. records ; nor was the occurrence of wave-and-spike or "petit-mal variant" patterns in a record essential for clinical or E.E.G. improvement to occur. Though the majority of those showing good clinical response did in fact show wave-and-spike activity, some cases without this improved markedly, and at least one case with a clear-cut wave and spike showed no clinical response to the drug.

\section{Toxic and Other Incidental Effects}

Blood changes are potentially the most dangerous and deserve special consideration. Reports of fatal blood changes have been mentioned above. They appear to be fairly sudden in onset and rapid in progress. In some of them both diagnosis and treatment seemed somewhat delayed. They may occur at any time within a few weeks to ten months of the start of treatment. As with other toxic blood dyscrasias, their earlier manifestations are probably general symptoms of sore throat, malaise, listlessness, etc. Their possible occurrence demands that patients on tridione should be under medical supervision, and unexplained general symptoms require an immediate check on the blood. They are, however, rare, and a more common effect noted by Davis and Lennox was a slow downward drift of the absolute neutrophil count, sometimes with a rise in number of lymphocytes or a transient eosinophilia. The change was reversed by omitting the drug.

In 36 of the cases in this series full blood counts were done at the start of treatment, thereafter fortnightly for the first six weeks, and then at intervals of four to six weeks. In 10 others the counts were done initially and at monthly intervals. In four the counts were more sporadic. In 26 cases treated for six months or more two showed a sudden marked reduction of total granulocytes in their monthly counts. Both returned to normal-one within 14 days and the other within four days of the abnormal count. In the latter case it was considered possible that the apparent reduction was due to a technical error. In six others a slow but irregular reduction of granulocytes was noted, but in none did the absolute neutrophil count fall to the 1,600 considered dangerous by Lennox. In four a moderate leucocytosis occurred, but at periods varying from one to 10 months after the onset of treatment, so that there was probably no causal link. In two an eosinophilia of over $5 \%$ was noted. No significant change in haemoglobin or red cells was seen.

The urine was tested, for albumin and sugar only, in 18 cases during the first three months of treatment. Albuminuria was found in one case. This was absent three weeks later, though the treatment had been continued.

Apart from the aggravation of grand-mal attacks considered above, other toxic effects, though annoying to patients, were medically trivial. Seventeen cases suffered from "glare." For this the wearing of sun-glasses during bright weather sufficed to allay any discomfort. Ten had rashes-eight acneiform, one macular, and one urticarial. In the latter two cases the drug was omitted for three weeks, as these rashes may sometimes herald more severe toxic reactions. The acne seemed purely an aesthetic disadvantage, though at times a serious one. In young women especially it proved a handicap to continued treatment, which had sometimes to be omitted temporarily. The rash would then clear, to return, though often less intensely, when the drug was restarted. Four patients had an irritability severe enough to affect their social relations. Three noted drowsiness and slight ataxia, and in one of them this persisted for some months. Three had prolonged bouts of hiccup during the first three months. None complained of indigestion, though two had nausea or vomiting at the onset. None of these complaints required more than a temporary cessation of the drug. It is a distinct advantage that its sudden complete cessation had no tendency to cause status epilepticus in patients with grand mal-a danger which always has to be borne in mind with barbiturates and hydantoins. 
The obverse of these minor ill-effects should also be mentioned. In many cases patients or their relatives spontaneously remarked on an increased sense of wellbeing, an improved performance at school, or improvement in social behaviour in the home. One intelligent patient gave a vivid description of the increase in selfconfidence when he no longer had to fear the sudden interruption of what he was saying or doing by an attack.

\section{Discussion and Conclusions}

There can be little doubt that tridione is a valuable remedy in the treatment of petit-mal epilepsy. At present it is used mainly in those cases in which phenobarbitone and the other better-established drugs have failed. In the future, it, or one of its less toxic related compounds such as dimethylethyloxazolidine dione, already in use in America, will probably be the drug of first choice. Its possible toxicity, especially to the blood, is a handicap, but as case material accumulates this will be seen to be a slighter risk than it appears at present. For the moment it should be used with circumspection, regular medical supervision and a routine monthly blood count being essential. As its use increases, a more serious disadvantage may be its aggravation or provocation of grand-mal attacks. For this the addition of some effective anticonvulsant will be required. Phenobarbitone may be useful here, but in this series the hydantoinates proved more valuable for combined therapy.

In the ten cases in which tridione seemed to activate grand mal this tendency was controlled in six by the addition of hydantoinates; and with these two drugs together three patients were rendered free from all fits for the first time for some years. Such a combination requires especial care in watching for blood dyscrasias, as both components are known to produce this effect. In practice, 17 of the above patients have been on this regime for periods up to 14 months, and so far no untoward results have been seen.

Short-term assessment of treatment in epilepsy is always apt to be misleading, because the frequency of the seizures tends to vary naturally, often for no apparent reason. Nevertheless, the first results of tridione therapy are striking enough to justify hope for the future.

Perhaps the most interesting question that arises out of this drug's marked selective effect on petit mal is that of its mode of action. Some valuable information on this point is provided by the findings of Grey Walter (1949 -personal communication). In patients who showed myoclonic jerks which could be fired off by photic stimulation, provided the frequency of the light-flash on the retina was exactly right, he found that administering tridione in a given case changed the frequency at which the light-flash would elicit the jerk. At first it appeared as if the lightstimulated response had been abolished; that the drug had "cured" this artificially stimulated epilepsy. But further stimulation with the light-flash at a changed frequency again produced the myoclonus, and it would seem that tridione had only altered the setting of the complex reflex pathway subserving the response.

In certain patients, at present few in number, the occurrence of clinical petit-mal seizures has been reported following intermittent stimulation of the retina by some incidental occurrence during their day's work (Cobb, 1947). In these cases any curative effect of tridione must work in a similar way to that demonstrated by Walter. If we consider that the central mechanism for firing off petit mal can be stimulated by other than photic afferent impulses-from exteroceptive and possible enteroceptive sources-then changing the rate of stimulus necessary to fire the mechanism would still provide a basis for clinical cure. There are many features in the clinical course of petit mal which would lend support to the view that incoming stimuli of various sorts help to precipitate the attacks.

Moreover, Jasper and Droogleever-Fortuyn's (1947) production in animals of generalized wave-and-spike cortical electrical patterns by stimulation of the internal laminar region of the thalamus also suggests the importance of the afferent system. Should these findings be applicable to human petit mal, then we must envisage the electrical changes in the cortex and the changes in consciousness that constitute the seizure as being activated from the thalamus. What causes the thalamus to fire in this way is still a matter for further experiment and speculation. But in interfering with the thalamo-cortical mechanism of the seizure tridione can presumably act at cortical or thalamic level or at both.

The findings from clinical use of the drug would suggest that some action at any rate is at cortical level. The "glare" phenomena support such a site, as does the change produced only in the aura phase of the two cases of grandmal attacks. Moreover, the effect on seizures occurring in the three patients with known focal cortical lesions point the same way. If this is so, then the continued use of tridione may enliven clinical routine by the incidental light it sheds on cortical function as well as by its therapeutic success.

\section{Summary}

A review of 50 cases treated with tridione is given -22 had one of the petit-mal epilepsies only, 24 had mixed grand and petit mal, three had grand mal only, and one had a unilateral tremor-rigidity syndrome.

In 31 cases the petit-mal attacks were abolished or markedly lessened, in 10 they were reduced, and in five unaffected. Grand mal was reduced in five cases, unchanged in 9, and aggravated .n 10, in one of which status epilepticus occurred.

Evidence of serious though transient toxic effects on the blood was shown in two cases. Other toxic effects included "glare," rashes, irritability, hiccup, drowsiness, and ataxia. Except for the first two, these were usually slight or transient.

The drug was discontinued in eight cases because it was ineffective or too provocative of grand mal, in three because improvement was maintained without it, and in one because of pronounced irritability.

The combined use of tridione and sodium diphenyl hydantoinate for the mixed epilepsies, and the possible mode of action of the former drug on the genesis of petit-mal seizures. is discussed.

Since writing this paper an additional five cases have been treated with tridione for periods of three weeks to three months. In three cases petit mal attacks were reduced to one-quarter or less of their previous frequency: in two there was little or no effect. Of the 37 cases from the original series who were continuing tridione, four have now ceased to take it. Three of these cases have maintained their improvement for one to three months. Blood changes have occurred in a further two casesin one there was a sudden drop in the absolute neutrophil count, which was reversed within three days by withdrawal of the drug; the other showed a slow reduction of neutrophils to 1,400 . In this case the total leucocyte count at first rose, owing to a simultaneous increase in lymphocytes. This emphasizes the importance of a differential count.

My thanks are due to Dr. W. Ritchie Russell for facilities for carrying out these trials. Messrs. British Schering, Ltd., kindly provided samples of trimethyloxazolidine dione at the start of this work. 
REFERENCES

Barnett. H. L., Simons, D. J., and Wells, R. E. (1948). Amer. J. Med., 4, 760 .

Braithwaite, R. F. (1948). British Medical Journal, 1, 14.

Briggs, J. N., and Emery, J. L. (1949). Lancet, 1, 59.

Butter, A. J.' M. (1948). British Medical Journal, 1, 13.

Cobb, S. (1947). Arch. Neurol. Psychiat., 58, 70.

Davis, J. P., and Lennox, W. G. (1947). Res. Publ. Ass. nerv. ment. Dis., 26, 423.

De Jong, R. N. (1946). Amer. J. Psychiat., 103, 162.

Everett, G. M., and Richards, R. K. (1944). J. Pharmacol., 81, 402. Forster, T. W., Watson, J. W., and Neumark, E. (1949). Lancet, 1, 517.

Greaves, R. J. (1946). J. Amer. med. Ass., 132, 44

Harrison, F. F., Johnson, R. D., and Ayer, D. (1946). Ibid., 132, 11.

Jasper, H. H., and Droogleever-Fortuyn, J. (1947). Res. Publ. Ass. nerv. ment. Dis., 26, 272.

Kerrin, J. C. (1948). Lancet, 1, 267.

Lennox, W. G. (1945). J. Amer. med. Ass., 129, 1069.

- (1947). Ibid., 134, 138.

Luton, F. H., Blalock, J., Baxter, J. H., and Stoughton, R. W. (1941). Proc. Soc. exp. Biol., N.Y., 47, 245.

Mackay, R. P., and Gottstein,'W. K. (1946). J. Amer. med. Ass, 132, 13.

Nattrass, F. J. (1949). British Medical Journal, 1, 43

Perlstein, M. A., and Andelman, M. B. (1946). J. Pediat., 29, 2 ).

Richards, R. K., and Perlstein, M. A. (1946). Arch.' Neuro'. Psychiat., Chicago, 55, 164.

Spielmann, M. A. (1944). J. Amer. chem. Soc., 66, 1244.

\section{THE USE OF “TRIDIONE" IN PETIT MAL}

BY

\author{
F. C. HAWARD, M.R.C.S., L.R.C.P. \\ Medical Officer, Chalfont Colony for Epileptics
}

"Tridione" was first used at Chalfont Colony for Epileptics in October, 1947. The following is a summary of the cases treated with this drug in the following year, with our conclusions.

As we knew little of the possible toxic effects of tridione the trial was limited to 50 cases, but we feel that these were sufficient to assess the efficacy of the drug. The patients were chosen at random; some suffered from petit mal alone and some from petit mal with grand mal. All cases of petit mal were diagnosed solely on clinical grounds. As tridione is effective only when petit-mal attacks are associated with a cortical dysrythmia of the wave-and-spike type, it is probable that some of the failures were due to the fact that the patients had a dysrhythmia of a different type. (Electroencephalographs were not available.) The ages of the patients ranged from 10 to 68 , and they were mostly females.

\section{Dosage}

Each patient began treatment with one capsule $(0.03 \mathrm{~g}$.) thrice daily; the dose was to be increased to six capsules daily if no benefit was produced. In only three cases was it necessary to administer the maximum amount. Initially, tridione was given to all cases, whether they suffered from petit mal alone or in combination with grand mal, but it was soon realized that tridione does not control grand mal. Moreover, certain cases who had previously only suffered from petit mal began severe grand-mal attacks when given tridione alone. Two cases went into status epilepticus (with subsequent recovery). We agree with Lennox (1947) when he states that he does not regard the term "anti-convulsant" as correct when applied to tridione in its use in epilepsy. An anti-convulsant such as phenobarbitone and/or epanutin is now given in conjunction with tridione to all cases.

\section{Duration of Treatment}

Anxiety about the possible toxic effects of tridione led to withdrawal of the drug too soon in some of the early cases. The continued administration of tridione with an anti-convulsant might have led to improvement in these cases, and we are at present treating some of them in this way. We have so far completely withdrawn the drug in only one patient (quoted below), who has reacted successfully. Lennox states that after the withdrawal of tridione there may be no attacks for 18 months. We gradually reduced the dosage when the fits ceased or became much less frequent. A number of patients whose attacks were considerably reduced with tridione showed an increase in attacks when the drug was discontinued owing to some contraindication.

\section{Immediate Effects}

Tridione is beneficial in cases of petit mal, a condition which had previously appeared not to react to any form of treatment. The results with some patients, particularly children, were dramatic. Within a short time of the drug being administered there was complete relief in patients previously having frequent attacks. One typical case illustrates this:

T. F.. aged 14 years 10 months. Admitted to Chalfont on April 29, 1943. He had suffered from 10 to 21 minor attacks per month for five and a half years. On Oct. 18, 1947, he was given tridione, one capsule t.d.s. Since that date he had one major attack, in November, 1947, and no epileptic attack of any type since. Prior to having tridione he was described as a "dopy " type of child; at present he is a bright and reliable boy and joins in all games with obvious enjoyment.

Apart from cessation or reduction of frequency of attacks, there has been improvement in behaviour defects and mental capacity in several cases, and the patients have expressed a feeling of general betterment. We have not been able to record improvement by the electroencephalograph, as the apparatus is not available. Lennox utilizes electroencephalography as an indication for reducing the dose of tridione. If his cases have had no petit-mal attacks for three months and the encephalograph is free of waveand-spike formations, he reduces the dosage by one capsule every two months until none is taken, if the attacks do not return. When reduction or cessation of attacks is not accompanied by an improvement in the patient's mental staté, this may be due to insufficient time having elapsed for the mental capacity to be judged. An improved mental state may follow, particularly in children and in cases with a short history.

In our experience the best results have been produced in children. Whether this is due to the age of the patient or the shorter duration of the malady we do not feel in a position to say, though Lennox states that the age is presumably the important factor. Age would appear to be no contraindication to the use of tridione. Our oldest case is a woman of 68 , whose history is appended:

K. A., admitted to Chalfont on Nov. 12, 1931, with 27 years' history of epilepsy-all minor attacks. Her annual number of attacks was from 150 to 250 . She was first given tridione on Nov. 21, 1947, since when she has had six to seven attacks per month.

In addition to the petit-mal attacks recorded by the attendants, presumably there are a large number which must escape observation.

One other factor in assessing the value of original treatment, particularly in adults, is the patient's suspicion of a new drug; in some cases this resulted in a lack of co-operation and hysterical manifestations. 